\title{
ACQUISITION OF DIGITAL COMPETENCE IN ICT COURSES FOR STUDENTS IN PEDAGOGY
}

\author{
D. Branekova* \\ Department for Information and In-service Teacher Training, Trakia University, Stara Zagora, Bulgaria
}

\begin{abstract}
Digital competence is one of the eight key competences, defined in the European qualification framework for lifelong learning, and it is a universal asset in the current computerized reality because it provides good educational perspectives and social prosperity. Digital competence is defined as skillful and correct use of electronic resources at work, for leisure and communication and is based on a high level of ICT literacy. Amongst the priority directions within the programs of Europe 2020 Strategy is the improvement and actualization of digital skills of all EU citizens regardless of their age, residence or economic status, so that they may participate fully in the digital society and the labor market. A key factor for promoting digital competence, which meets the requirements for information society as early as school age, is the role of teachers, their university formation and continuous postgraduate qualification.

The present study focuses on specifying the conceptual meaning of "digital competence" for students in pedagogy, formed in the process of their education. The debatable character and different interpretations of the more general term "competence" invite different definitions of "digital competence". The complex character of teachers' integral professional competence complicates the creation of a universal content framework of digital competence. In this sense the present study is limited to determining the fundamental meaning of digital competence, and it serves as a basis for further analysis of different ICT education models in the training of students in education.
\end{abstract}

Key words: Key Competencies, Computer Skills, Information Technologies, Interactive Models of Information Technologies Training, Web 2.0

\section{INTRODUCTION}

Today's world of globalization and rapid change requires current and future students to acquire knowledge and develop skills necessary for economic and social success in the 21 st century. On the other hand the hightech environment of many areas of our lives, including the education sector, requires specific competencies.

According to "Europe 2020" Strategy and the Program for modernization of higher education systems, one of the main goals is to enforce the link between education, research and business. This goal has to do with investing in skills that are defined as strategic contribution to growth, better social and economic outcomes. Higher pedagogical education prepares highly qualified teachers who are responsible for the

\footnotetext{
*Correspondence to: Dimitrina Branekova PhD, Trakia University - Department for Information and In-service Teacher Training, 9 Armejska Str., 6010 Stara Zagora, Bulgaria, dbranekova@unisz.bg, phone \#359-42-633024, GSM 0887144353
}

training and education the prospective workforce needed in Bulgaria and Europe.

Today's students in education will instruct a generation which is expected to generate innovation as a basis for improving the quality of life. Future teachers will have to be trained to be closer to the current generation of students who already have another way of perceiving the surrounding environment, different learning styles and skill formation under the influence of digital technologies.

\section{PURPOSE OF RESEARCH:}

Defining the content frame of digital competence as a basis for studying and approbation of different models for information technologies in the preparation of student teachers.

RESEARCH METHODS: Comparative theoretical analysis, polling, observation

\section{RESULTS AND DISCUSSION \\ Problematic fields of the study}


The Bulgarian school needs well-prepared teachers who can use modern technologies in their teaching and learning management. This preparation usually is linked to the possession of digital skills which are referred more and more often to universal skills with a higher degree of transferability in the area of education. The topic of the study is closely related to the following discussion problems which pedagogical theory and practice are facing:

- Origin and interpretations of the concepts "competence" and "competency" and the relationship between them

- Inclusion of digital competence in the educational and professional competence of teachers

- Creation of a cluster of digital competencies for the teaching profession for digital competence at a basic level and for digital competence at an expert level

\section{Digital skills in the context of Europe 2020 Strategy}

At the root of the "knowledge triangle" from the declaration of the EU in Bologna is the quality of higher education, innovations and academic research. Qualified experts, including educators, must be capable of working in the current information society where the constant modernization of knowledge and skills is of paramount importance for the professional adaptivity of people.

In the EC guidelines quality education for developing the skills of the 21 st century is associated with "utilizing the potential of the information and communication technologies (ICT) and the open educational resources (OER)." Open Educational Resources are teaching, learning or research materials that are in the public domain or released with an intellectual property license that allows for free use, adaptation, and distribution“"(1).

Technologies offer unprecedented opportunities for improving quality, access and equity in education and training. E-learning, as well as the recent trends in the open educational resources (OER), creates an open space for changes in education beyond traditional forms and limits. Due to the increasingly widespread use of OER through Internet there arise new forms of learning that offer more personalized approaches, commitment, use of digital media, collaboration and practices of a "bottom-up" type in which the student or the teacher himself becomes an author of educational content. Europe should take advantage of the potential of OER in a much greater extent than at present. [idem.] For this purpose, good computer skills of all employees in the educational process - teachers, university students and students at school, are needed. Digital competence is one of the eight key competences, that is defined in the European framework for lifelong learning as a skillful and proper use of electronic means in work, leisure and communication purpose. This competence is based on consistent and accurate thinking and a high level of proficiency in electronic technology (computer, multimedia, Internet, communication, ATMs, mobile phones, etc.) (2)

\section{Digital competencies and digital competence}

Competences, as a component of the professional training of students are related to what the European qualification framework defines as the results of education: "A combination of knowledge, skills and competencies, acquired by an individual who can demonstrate them after completing his education" (2). Training in educational majors aims to fulfill the requirements for professional competence acquired by the teacher who in turn needs to practice his profession under the present conditions.

Many authors study the origin of the terms "competency" and "competence" and the relationship between them. The analysis of the two terms has a long history, which has resulted in the existence and practical use of different definitions. Often, these terms are used interchangeably, for instance in the EU documents for education. In order to clarify the essence of the term "digital competence" we must analyze the broader sense of "teacher's professional competence" and "educational competence" (3). V. Velikova defines "educational competence as a result of educational activity" (3). She comments on the Latin root of "competency", specifying the term "competence": "competo" means "coincide; match; to be capable of", "competentia" - "commensuration, proportion" and "competenter" - "as it should be".

As she analyzes "the logic of these meanings, and the use of the term" Velikova defines competence as "well-structured in the brain ability as it should be, determined by higher levels of knowledge, values and actions, demonstrated through its corresponding skills" $(3,15)$. In their study on the structure of teacher's professional competence, Najdenova and Genkova define competence as a "system of competencies on specific areas" $(4,8)$. In the same study the authors make a comparative 
analysis of the term "competence" and its related terms "awareness, experience, learnedness, skillfulness, professionalism, erudition". The authors define "professional competencies as a component of professional competence and as complex personal structures, formed after acquiring a specific group of knowledge, skills, experience and behaviour in a given area of professional activity" (4, 11). Milkova defines the term "competency" as a "result of education preparation, adaptability, achievability of aims, whereas the term "competence" is defined as a complicated integral personal quality, which is revealed as its general ability and readiness for action, based on knowledge and experience, acquired during education, training, upbringing and socialization, and oriented towards independent and successful participation in the activity" $(5,46)$.

The development of the new 21st century skills, according to "Europe 2020" Srategy, the Program for the modernization of the higher education systems and the European Framework of Key Competences for Lifelong Learning is based on the competence approach. This is because this approach allows people to flexibly and adaptively use their knowledge and skills to pursue their personal goals - they know their limits and select an environment in which they can act competently and feel effective. Moreover, such an approach helps ensure a higher degree of connectivity between individual experience of knowledge and skills and the social goals of the individual and the society. The main concept in this approach is "competence", which cannot be clearly distinguished from the term "competency" and the two terms are often used interchangeably.

In regard to the exact meaning and the relations between the terms "competencies" and "competence" the following conclusions can be drawn:

- The etymology of the two terms is common, but the different authors and schools imply semantic differences between the two terms

- There are different interpretations of the meaning of the two terms depending on the standpoint of their clarification

- The majority of authors claim that competence is a more general term and is related to personal qualities, whereas competency is more objective and has a marked concrete and objective sense

- In the European educational space "competence" and "competencies" are used as synonyms; in the European referential framework and in the National strategy for life-long learning the terms used are "professional competences" and "key competences"

- In terms of curricula in the different educational degrees the competencecompetency relationship is like that between a goal and an achieved result, but in the broader sense, competency is seen as the result of accumulated competencies.

For the purposes of the present study we assume that competency is usually presented as a set of interconnected understanding, skills, habits, methods of taking action, that are required for a specific range of subjects and processes and needed for any related efficient work of quality. Competence is the acquisition and exercising of a corresponding competency, including their personal attitude towards it and the purpose of the activity. Competence is defined as multiple innate or acquired personal characteristics, attitudes, knowledge and skills leading to high-quality performance.

In this sense, skills are built based on the qualities, attitudes and knowledge of the person. In terms of competences in the learning process, the skill can be seen as the practical result of learning, knowledge as the contribution of learning to the development of the skills, and attitude as an acquired behavioral pattern influenced by internal and external motivation and features such as predisposition associated with the innate abilities.

In the European referential framework for lifelong learning (EQF) digital competence is defined as the skillful and correct use of electronic devices for work, leisure and communication purposes. This competency is based on logical and exact thinking and on a higher level of mastery of electronic technologies.

In the information system for competency evaluation in Bulgaria sector models in different areas of economics have been developed and where competencies re described in three clusters: basic, specific and management. Digital competencies exist in all sector models as a cluster of digital competencies at a basic and expert level for the teaching profession.

European e-Competence Framework is a competence method created to work at a European level. Its main purpose is to create a sustainable solution for the development of digital skills (7). 


\section{Digital competence of student teachers}

One of the main objectives of the IT training of student teachers is the formation of digital competence as a set of personal qualities (existing and acquired), knowledge, attitudes and skills. Each competence, apart from cognitive knowledge and skills, also includes skills and attitudes, willingness and ability to learn. The specifics of the teaching profession requires teachers' constant readiness for learning and formation of compulsory social interaction skills, tolerance, empathy, mechanisms for self-reflection, etc. which facilitate the acquisition of universal (key) competencies, i.e. digital literacy should be viewed more broadly as informationcommunicative competence.

Through various forms of training methods, teacher's efforts are aimed at developing and improving learners' computer skills, introducing educational software suitable for their future profession, and preparing students methodically for the integration of information technologies with the other subjects. Basic computer skills are a necessary prerequisite for the development of digital competence.

Research on previous experience and pedagogical research in the field of computer education show that computer skills are most commonly taught as an object, e.g. skills at a certain level of computer literacy are formed. It is a compulsory part, but it represents only a single part of the digital competence. The other side suggests the formation of common habits in thinking like searching, comprehending, grading, systematizing and using information in different environments such as coping with professional, personal or global problems. Proper knowledge of computer skills can be formalized and assessed impartially. For example, ECDL (The European Computer Driving License), is the most common certificate for computer skills acquired by over 3.5 million people in recent years. For acquiring it, a network of representatives in more than 140 countries. The questions in ECDL are organized in such a way that the level of certain skills can be assessed, regardless of the used computer platform. Each question covers a unit of knowledge in a certain field, which is a part of category of seven modules representing the most commonly used IT. In other words, grading the results of training in acquiring computer skills can be achieved and every instructor does it. Such certifying, however, assesses only technical skills, not competences.

Digital competence of students in education is not the subject of a single course, but rather a degree-long study, along with their specialization training.

As we establish a meaningful framework for digital competence in the training of studentspedagogues we define the following directions: Transition from forming skills (and their evaluation) for a particular information technology towards generalized skills as the basis for the transition unit ability competence;

The formation of generalized skills is directly related to the teaching profession of the students and the object of their future activity training of students.

These directions determine the content focal points in the syllabus for ICT in Education course for students of Pre-School Pedagogy and Elementary School Pedagogy with a Foreign Language at the Pedagogical Faculty of Trakia University.

In view of course design an empirical study of how students evaluate themselves about their own level of computer knowledge and skills. In the survey we included questions to students for self-evaluation of their own level of knowledge and skills for work with information technologies for processing various types of information, and for preferred mobile and web-applications. The Selfevaluation was compared to results obtained from a test with the same students. The results from the empirical study appear in Figures 1, 2 and 3.

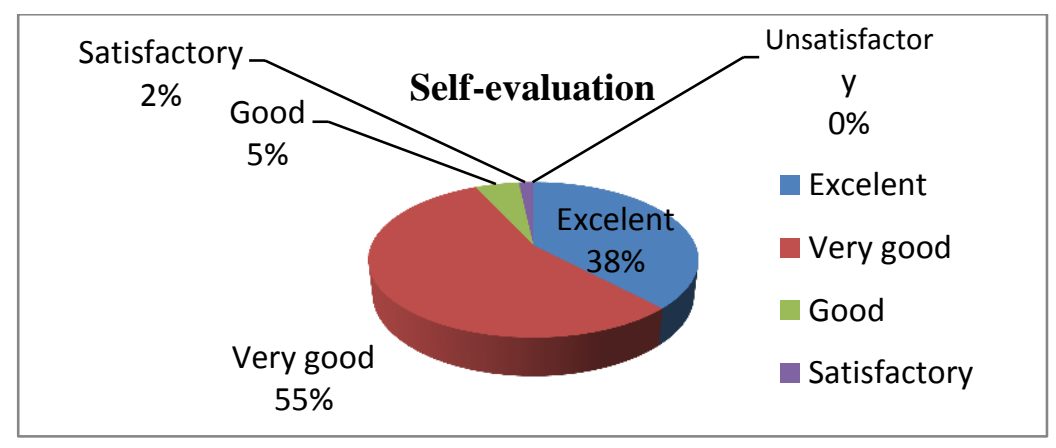

Figure 1. Self-evaluation of first-year students, 2015, spring semester 


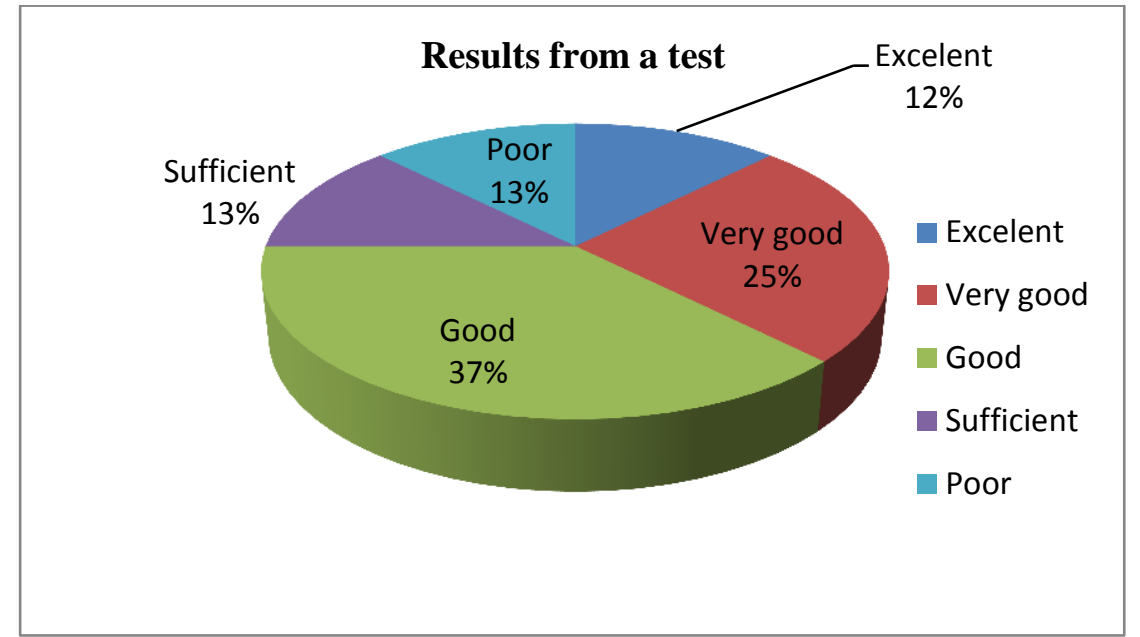

Figure 2. Results from a test of first-year students, 2015, spring semester

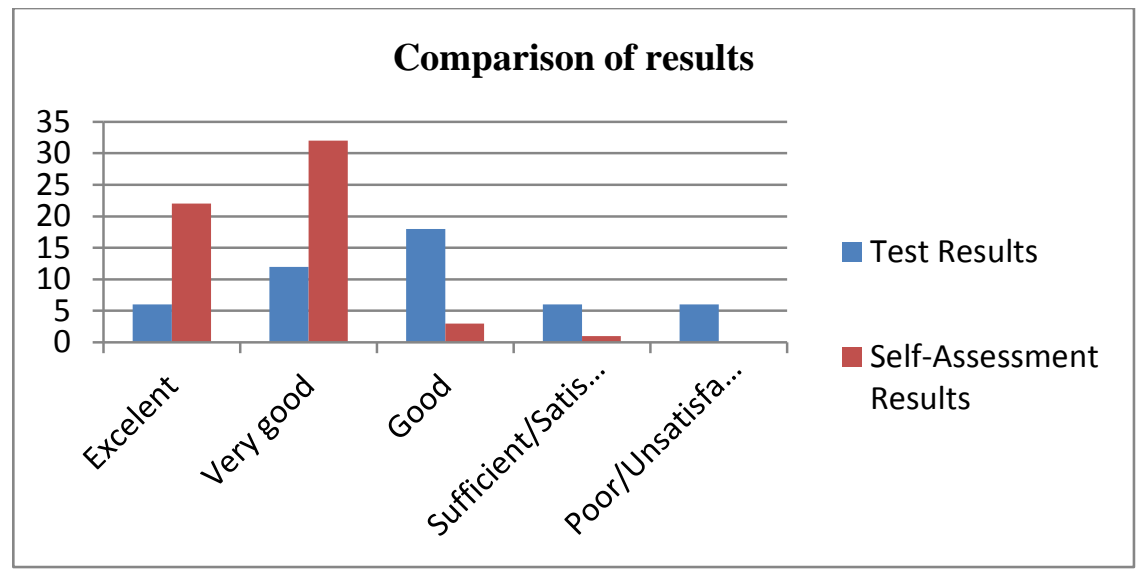

Figure 3. Comparison of results

Judging from the comparative analysis of the self-evaluation and the achievements of students, a conclusion can be drawn about the necessity of education for catching-up at the basic level of computer knowledge and skills, needed to form digital competence, as a part of teacher's professional competence. In comparison to knowledge and skills, as a result of educational activity, competencies are expressed and defined in specific activities. For the transition from "knowledge and skills" to digital competencies and competence the following two conditions must be met:

- Computer knowledge and skills must be integrated in the framework of a common model of information processing

- Computer knowledge and skills must be related to a specific subject matter - profile training of students through assignments such as projects, course portfolio, didactic materials, etc.

Meeting the two conditions defines the content frame of digital competence formation:

- Defining the information problem -A task which suggests performing essential tasks - gathering, editing, saving and spreading information.

- Access to information resources:
- Searching, grading and using available resources;

- Creating own resources.

- Choosing technology to solve the problem:

- Knowing the capabilities and the restrictions of information technologies in a certain situation;

- Choosing and combining appropriate technologies.

- Creating information model:

- Skillful use of means for creating and editing different computer documents;

- Creating integrated computer documents.

- Grading the information model:

- Grading the strong and the weak points of the information model;

- Self-reflection on every step and improving of the model.

This content framework presents the general and specific knowledge, skills, relations and qualities related to the level of fluency (basic and expert) of the means of the relevant information technologies. If we add to them general skills, which are formed throughout the whole course of education, as well as the innate and acquired personal qualities, we can draw a model of digital competence of student pedagogues (Table 1). 
Table 1. A model of digital competence

\begin{tabular}{|c|c|c|c|}
\hline Cognitive Skills & IT means & Personal Virtues & \begin{tabular}{|l|} 
Social Skills \\
\end{tabular} \\
\hline $\begin{array}{l}\text { Description of the } \\
\text { information } \\
\text { problem }\end{array}$ & $\begin{array}{l}\text { Basic level } \\
\text { Computer text } \\
\text { editing } \\
\text { E-communication } \\
\text { Expert level } \\
\text { Web 2.0 }\end{array}$ & \multirow{5}{*}{$\begin{array}{l}\text { - Identifying } \\
\text { personal needs and } \\
\text { priorities; } \\
\text { - Defining goals; } \\
\text { - Planning; } \\
\text { - Learning from } \\
\text { past experience; } \\
\text { - Self-reflection; } \\
\text { - Forming } \\
\text { arguments ; } \\
\text { - Impartial } \\
\text { judgment; } \\
\text { - Interactive use of } \\
\text { knowledge and } \\
\text { information. }\end{array}$} & \multirow{5}{*}{$\begin{array}{l}\text { - Teamwork; } \\
\text { - Sharing and } \\
\text { cooperating; } \\
\text { - Presenting ideas; } \\
\text { - Perceiving } \\
\text { another's ideas; } \\
\text { - Empathy; } \\
\text { - Effective emotion } \\
\text { management }\end{array}$} \\
\hline Access to resources & $\begin{array}{l}\text { Basic level } \\
\text { Google, Yahoo, } \\
\text { Rambler, etc. } \\
\text { Web 2.0, FTP } \\
\text { electronic resources } \\
\text { - CD, servers, etc. } \\
\text { Computer text } \\
\text { editing } \\
\text { Computer graphics } \\
\text { Information } \\
\text { systems } \\
\text { Expert level } \\
\text { Web 2.0 } \\
\text { Mobile applications }\end{array}$ & & \\
\hline $\begin{array}{l}\text { Choosing } \\
\text { technology }\end{array}$ & \multirow[b]{2}{*}{$\begin{array}{l}\text { Basic level } \\
\text { Computer text } \\
\text { editing } \\
\text { Computer graphics } \\
\text { Electronic tables } \\
\text { Databases } \\
\text { Computer } \\
\text { presentations } \\
\text { Expert level } \\
\text { HTML } \\
\text { Web design }\end{array}$} & & \\
\hline $\begin{array}{l}\text { Creating } \\
\text { information model }\end{array}$ & & & \\
\hline $\begin{array}{l}\text { Grading the } \\
\text { information model }\end{array}$ & $\begin{array}{l}\text { Basic level } \\
\text { Educational } \\
\text { software } \\
\text { E-communication } \\
\text { Expert level } \\
\text { Web } 2.0\end{array}$ & & \\
\hline
\end{tabular}

Building digital competence is carried throughout the whole course of student training, both in IT courses, and in the context of the application of the technologies in their professional training.

\section{Training models for formation of digital competence \\ eLearning}

In the training of students in both Master's, and increasingly more in Bachelor's programs, it is agreed that the preferred form of training will be the one which combines elements of distance and traditional learning, and also that which integrates ICT tools and methods with conventional methods and means. ICTs facilitate the implementation of distance learning in various aspects: promotion and motivation for learning, its organization, creation of a new learning environment, and diverse learning materials depending on the purpose and objectives of the specific training, etc. With the development of technologies modern distance learning includes elements of electronic, computer-oriented, web-based training, etc. Electronic university courses consist mostly of a certain set of training modules. Each module includes topics in which teaching content and specific learning activities are described, such as lectures, seminars, exercises, project work, etc.

In Trakia University, Stara Zagora, an elearning platform is established and is approbated under "Development of a center for electronic forms of distance learning" project within "Human Resources Development" operational program. The design of each topic 
includes the following sections:

Training materials - text, audio, video, and self-study materials for learning essential information;

Summaries, self-evaluation, control - this section contains a summary, abstract of the theoretical material, keywords, a practical task for the new concepts and a test for self-control on the subject;

Additional materials - the section contains slides to illustrate technologies for performing basic operations in a computer environment, resources for solving practical problems, internet sources on this topic and others.

The e-learning platform on the one hand requires students to have digital competence, and on the other hand the platform itself for its attractiveness and advantages for distance learning motivates students to improve their skills and acquire a pattern of behavior that facilitates the development of digital competence.

\section{Web 2.0 tools in education}

Web 2.0 is an environment for collaborative work, suitable for the goals of the training in information technology, which in addition to forming purely technological skills, forms and personal qualities such as cooperation, sharing, teamwork, etc. Web 2.0 as a cloud technology can combine, enrich and build on both electronic and traditional forms of education in information technology. Electronic forms of training strengthen the individual work of the students and facilitate the access to various resources.

University courses comprise a set of training modules. Each module includes topics in which besides teaching content, there are specific learning activities - lectures, seminars, exercises, project work, etc. In the educational e-learning resources the content of the learning process is concentrated through e-learning. The importance of these resources is significantly greater than that of the resources in the traditional training because they have to compensate for the lack of direct contact between learners and instructors.

In the process of developing an e-learning course the author must structure and prepare as files the necessary teaching materials, covering the educational content - outlines of lectures it would be best if written as structured texts; additional texts in the form of readers; demos multimedia presentations, videos and films; practical assignments - creative or samples with provided instructions and guidelines; tests, checklist for self-control and others. Also, the author of the course should organize the individual work of the group through dialogic instruction for the relevant course. Electronic forms for distance education of this kind are based on the first generation Internet technologies, the so called Web 1.0 technologies. The electronic course with all its positive aspects, is a virtual, yet limited classroom or auditorium, with a fixed number of participants and with a strictly defined framework of objectives and course content. Internet Web 2.0 technologies allow the classic e-learning to develop in the direction of easier access to resources, "opening" of the virtual audience for active participation and sharing of many participants, independence from software and technical support. Web 2.0 combines the second generation web based services and represent the development and improvement of the Web1.0 technologies. The basis of the applications and the Web 2.0 technologies are collaboration, online collaboration and sharing among users. Kisimov and Velev define "Web 1.0 as a static environment in which you can find information, rather than a forum for exchange of ideas or a space to create new products. Web 2.0 is an Internet environment in which the users can actively interact and participate in various processes, not just passively read published materials from other participants "(8).

In the studios of Kisimov and Dobrev Web 2.0 applications are grouped into the following main groups: blogs, social networking, video and photo material exchange, wiki, online maps, virtual worlds. They are implemented through relevant websites. Atanasov compares Web 2.0 with a universal operating system, offering access to all applications and services for which you only need a web browser with Internet access (9).

\section{Didactic possibilities of shared documents}

The basic skills that are formed in the training in information technology are related to the creation and integration of documents containing various information objects - text, tables, charts, diagrams, slides, graphics and others as well as skills for using the network resources.

Google documents are a part of the most commonly used Web 2.0 tools. With Google documents there can be realized many of the practical exercises on information documents by providing:

- Creating documents, spreadsheets and presentations online; all known functionalities are available directly in the browser - making lists, tables, images, 
comments, formulas, various formatting means, etc.;

- A new file organization that gives the user independence from specialized software for documents and provides ability to work from any computer with an Internet connection and an ordinary web browser. Documents are stored online and changes are saved automatically - regardless of the external memory of the local computer;

- Collaboration on documents of multiple users in real time.

Using Google Docs requires a different style of organization of the training in information technology. The rich applications and the very user-friendly interface suggest a brand new didactic solutions for different learning situations for the creation and integration of documents with a variety of information models. File sharing and controlling the access to them helps the teacher in the management of the learning process. The possibility of multiple users to simultaneously edit files and monitor the work of others creates good conditions for group work, team work, project work, etc. Products made through the sharing of documents facilitate the support and participation in a blog of the teacher or the students, posting on social networks, inclusion in the wiki in the development and transformation of content, etc.

\section{CONCLUSION}

Digital competence is a part of the professional competence of student teachers. Digital competence allows various problems to be tackled, improves communication, organization of pedagogical activities and situations, and fosters research and creative work.

The models for learning through Web 2.0 applications with its sharing capabilities, collaboration, social engagement and more, as well as e-learning are a modern tool for the realization of educational environment close to the interests and daily lives of today's students. These innovations also facilitate the access to education, postgraduate training and continuing education.

Technology and Web 2.0 applications are available to all, they are a reality, they fit in all social spheres, including education. The use of Web 2.0 tools in teaching and the possibility for upgrading e-learning allow the transition from formation of basic computer skills to building of digital competence to take place.

\section{REFERENCES}

1. Commission Communication to the European Parliament, the Council, the European Economic and Social Committee and the Committee of the Regions. Rethinking education: investing in skills to achieve better social and economic outcomes. Strasbourg, 20/11/2012 COM (2012) 669 final.

2. European Qualifications Framework for lifelong learning (EQF). European Commission, Luxembourg: Office for Official Publications of the European Communities, 2009.

3. Velikova V., Educational competence as a result of pedagogical work //Pedagogy, № 6:3-19, 2003.

4. Najdenova V., L. Genkova, Structure of teacher's professional competence. //Education and Qualification, № 3:8-20, 2000.

5. Milkova R., Competency and Skills of the Person - Strategy of University Education during $21^{\text {st }}$ Century. //Strategies for Policy in Science and Education, Vol 23, № 1:3864, 2015.

6. Informational System of Competency http://mycompetences.bg

7. European e-Competence Framework. http://www.ecompetences.eu

8. Kisimov, V., D. Velev. Metods for design of business information systems based on Web 2.0 Cloud Copmuting. www.research.unwe.bg/br17/5.pdf

9. Atanasov, G. Web 2.0-A new world with (un)limited opportunities http://www.computers.bg/web_20_edin_n ov_svqt_s_neogranicheni_vyzmojnosti.htl 